\title{
PCM incorporation in a concrete core slab as a thermal storage and supply
} system: proof of concept

\author{
Lidia Navarro ${ }^{\mathrm{a}}$, Alvaro de Gracia ${ }^{\mathrm{a}}$, Albert Castell ${ }^{\mathrm{a}}$, Servando Álvarez ${ }^{\mathrm{b}}$, Luisa F. Cabeza ${ }^{\mathrm{a} *}$ \\ ${ }^{a}$ GREA Innovació Concurrent, Universitat de Lleida, Edifici CREA, Pere de Cabrera s/n, 25001, Lleida, Spain \\ Tel.: +34 973003576, E-mail address: lcabeza@diei.udl.cat \\ ${ }^{b}$ Grupo de Termotécnia, Universidad de Sevilla, Escuela de Ingenieros Camino de los Descubrimientos s/n. 41092, Seville, Spain
}

\begin{abstract}
Phase change materials (PCM) has been widely implemented in buildings envelope as passive system as well as in storage tanks for active systems. A new promising technology has been designed to act as a hybrid system between the passive and active ones. The main idea is using the internal slab as a thermal energy storage system to cover partially the energetic demand both during heating and cooling periods. This innovative constructive system consists of a prefabricated concrete slab with PCM macro-encapsulated in small tubes and inserted in its hollows. A direct cross-flow heat exchange occurs between the air pumped into the slab and the PCM for conditioning purposes. A prototype has been implemented in a two storey house-like cubicle and has been tested under real conditions, where the slab becomes a thermal storage and supply component. The objective is to study the thermal performance of the slab and its components, in a theoretical analysis, as well as the suitability of the system in a Mediterranean continental climate. The concept was proved experimentally and compared to the theoretical results to demonstrate the potential of the technology. However, experimental results remarked the importance of a further investigation under real operating conditions.
\end{abstract}

Keywords: thermal energy storage (TES), phase change materials (PCM), concrete core slab, building, space heating, solar air collector

\section{Introduction}

Energy coming from the building sector has become an important amount of the global energy consumed in Europe [1]. Since the Horizon 2020 programme was implemented with the objective of $20 \%$ reduction of the greenhouse gas emissions by 2020 as one of the main statements [2], professionals of the building sector must take into account the energetic performance in their designs. These new policies give importance to the research and development of technologies focused on the energy demand reduction in buildings, in order to achieve zero or nearly zero energy buildings. Moreover, they also promote the use of renewable energies to cover the remaining demand.

Nowadays, in buildings regulations, solar energy is considered as a solution to reduce the energy consumed by buildings [3]. However, a disadvantage of this kind of renewable energy is the gap between supply and consumption [4]. In this context, researchers are working on improving an important issue related with the energy, storage. Energy storage technologies are an important part of the system to ensure that the energy supply is available to the end user. Thus, the energy storage system plays a very important role to define the energy efficiency of HVAC systems [5]. 
A promising technology of energy storage is the use of phase change materials (PCM) [6]. In this case, the latent heat absorbed and released during the change from solid to liquid is used. These materials are able to store large amounts of thermal energy. In addition, PCM works in a specific temperature range (phase change temperature) which allows the design of the system to be related to the desired application for obtaining the maximum amount of energy. The implementation of thermal energy storage, and in particular PCM, in buildings has been widely studied [7-9]. An important part of the literature is focused on the passive and active applications of latent heat storage materials. Building envelope improvements are well known for having high potential on energy demand reduction, but are usually studied with passive systems. PCM in gypsum board for thermal mass enhancement of the walls [10]; in prefabricated concrete walls for thermal inertia increase and lowering peak internal temperatures [11]; and the inclusion of macro-encapsulated PCM placed in the constructive system of the building facade [12] are some examples of passive systems which registered improvements on the energy performance of buildings.

Regarding the active systems, two main groups can be distinguished. The first group is the inclusion of PCM into the HVAC equipment, air handling units or storage tanks. Lazaro et al. [13] designed different PCM heat exchangers in order to take advantage of the night free cooling. The implementation of PCM in domestic and solar water tanks was used to provide thermal stratification [14]. Moreover, PCM storage tanks are also implemented in heat pump devices, such as Hamada and Fukai [15] that connected two different storage tanks to the condenser. A specific place needs to be assigned for the installation of these storage systems in the building, which it is usually an important drawback for the architect/engineer or even for the final user.

On the other hand, the second group of active systems is able to solve the main disadvantage of the previous one. It consists of using building components as thermal storage and energy supply systems, hence empty spaces of the building structure are used to locate those systems. A double skin facade with PCM [16] was designed to absorb and store the solar energy, in order to cover the heating demand. The study demonstrates the potential of the technology achieving energy savings between 19\% and 26\%. Barton et al. [17] presented the TermoDeck hollow core slab which utilises the hollow cores of a pre-cast concrete slab as ventilation ducts for cooling purposes. Taking advantage of the night free cooling, the concrete is cooled down and during daytime the cold is passively discharged. Using the same building component, Pomianowski et al [18] studied a prefabricated concrete ceiling deck element with integrated water pipes with an additional layer of concrete with microencapsulated PCM.

Although they are classified in the active systems group, some of these systems, such as the concrete slab ones presented above [17,18], are designed to produce a thermally stable environment because of its passive discharge. However, this could be a limitation in an application where a fast cooling demand is needed. Moreover, most of these building storage components are not designed to provide heating and cooling with the same technology, as well as they are not able to provide a night free cooling supply. Table 1 presents a brief comparative of some technical aspects of the systems mentioned above.

In this paper, an innovative integrated active system is presented. A pre-cast concrete slab is used as storage and supply system to reduce the heating and cooling consumption of HVAC systems. Both charge and discharge are active and the addition of PCM inside its hollows provides higher thermal storage capacity. 
The presented system has been designed for heating and cooling applications. The winter operational principle consists of melting the PCM during the daytime with hot air provided by a solar air collector. Once there is a heating demand the air is pumped inside the hollows taking advantage of the heat exchange with the melted PCM. On the other hand, during summer the PCM is solidified through night free cooling for a later discharge when the temperature starts to rise up.

The present paper is focused on a theoretical analysis of the thermal response of the slab components (concrete and PCM), the storage efficiency, and the suitability of this technology under a Mediterranean Continental climate. Moreover, the system concept is tested in an experimental set-up and compared to the theoretical results. As a proof of concept study, one of the main objectives is to demonstrate that the PCM selected has significant storage potential for both winter and summer seasons in order to provide heating and cooling supply. In addition, the performance of the technology will be analysed taken into account the efficiency of the system and proposing improvements if needed.

\section{Concept}

\subsection{Prototype description}

The installed prefabricated concrete slab is a commercial element widely used in new and already existing buildings. The component has a thickness of $30 \mathrm{~cm}$, with a surface of $2.4 \mathrm{~m} \mathrm{x}$ $2.4 \mathrm{~m}$ and it is formed by 14 channels where the PCM is located. A hole at the beginning and end of each channel allows the air flow into the slab. Moreover, under these holes an air duct installation is implemented with 6 gates (Madel CTM-AN 250x200 mm) and a fan (Sodeca CMP-512-2T) of $80 \mathrm{~W}$, which permits different operation modes. The fan could operate under different air flow velocities and during these experiments the air flow rate measured was 0.0781 $\mathrm{kg} / \mathrm{s}$. A solar air collector with a surface of $1.3 \mathrm{~m}^{2}$ and a power rating of $1330 \mathrm{Wp}$ (AIRSOL-20) which integrates a fan connected to a photovoltaic panel is implemented in the south facade as a heat supply for the winter mode and it is coupled to the rest of the active system. Thus, the air can be taken and blown from indoors, outdoors or from the solar air collector, depending on the used operational mode (Figure 1).

As it has been previously stated, the system has been designed both for heating and cooling. In order to ensure its suitability for both periods the selected PCM is RT-21 with a phase change temperature around $21{ }^{\circ} \mathrm{C}$. That is an appropriate temperature for heating and cooling systems, since it is inside the comfort temperature range of buildings [19]. The properties provided by the manufacturer and the ones measured by the authors in the experimental facilities and with the differential scanning calorimeter are shown in Table 2.

PCM is macro-encapsulated in aluminium tubes of $12 \mathrm{~mm}$ diameter and $100 \mathrm{~mm}$ of height, which are fixed in wood structures following criteria of heat transfer enhancement between the air and the PCM in cross-flow (Figure 2). The total number of tubes installed is 1456 that contain $52 \mathrm{~kg}$ of RT-21. 
129 During the winter period (Figure 3a), the active slab is used as a heat store and supply for 130 covering partially or totally the demand (depending on the weather and the energetic 131 requirements). During the daytime, the solar radiation heats the air inside the solar air collector 132 located on the south facade. Hot air is injected into the slab and used to melt the PCM. 133 Depending on the programed schedule, the air heated by the solar collector can be also used to heat up the internal ambient air if required by the demand. Once the daylight is over, the active slab works as a storage component integrated in the building structure. It should be taken into account that the concrete plate has also an important role in the storage period, since it is composed by a material with high thermal mass. Then, during the discharge period, indoor air is pumped through the slab and a heat exchange occurs between the cool air and the warm PCM, providing a heating supply to the cubicle.

On the other hand, the operational mode during the summer season (Figure 3b) is based on night free cooling. When the external temperature is below the phase change temperature $\left(21^{\circ} \mathrm{C}\right)$ outside air is injected inside the slab to solidify the PCM. The storage period starts once the PCM is completely solid and no more free cooling is required. During the day, when a cooling demand is needed, the internal ambient air from the cubicle is pumped through the slab and cooled down due to the heat exchange with the PCM, covering part of the cooling loads. At night and during the solidification process of the PCM, the air could also be used to cool down the internal temperature of the cubicle.

\subsection{Design parameters}

Both winter and summer modes have their significant design parameters which define the available energy that the system can store during the charging periods. The higher the charged energy is, the higher the benefits the active slab can achieve are. For this reason, authors studied the suitability of the phase change temperature of the PCM used against the climatic conditions of Puigverd de Lleida (Spain) where the experimental facility is located.

In the case of summer, the charging period consists of solidifying the PCM during night time; hence, temperatures below $21{ }^{\circ} \mathrm{C}$ are needed. Temperature evolution from June to September, registered by the weather station located in the experimental facility (Puigverd de Lleida, Spain), was analysed in order to evaluate the climate potential to solidify the PCM at night.

The daily available power $\left(\mathrm{P}_{\text {available }}\right)$, defined by the power achieved from temperatures below 21 ${ }^{\circ} \mathrm{C}$ at night to solidify the PCM, is calculated for all the summer season through Eq. (1). On the other hand, the daily required power $\left(\mathrm{P}_{\text {required }}\right)$ to solidify the total amount of PCM incorporated 161 in the slab is obtained with Eq. (2) which depends on the period of time $\left(\mathrm{t}_{\mathrm{av} . \mathrm{out}}\right)$ that outside temperature is below $21{ }^{\circ} \mathrm{C}$ at night.

$$
P_{\text {available }}=\dot{m} \cdot C p_{\text {air }} \cdot\left(T_{p c}-T_{\text {av.out }}\right)
$$

where, 
$P_{\text {required }}=\frac{m_{p c m} \cdot L_{p c m}}{t_{a v . \text { out }}}$

where,

$m_{p c m}$ is the total PCM mass incorporated in the system, $L_{p c m}$ is the latent heat of fusion, and $t_{a v . o u t}$ refers to the period of time that outside temperature is below $21^{\circ} \mathrm{C}$ at night.

Both power values are compared in Figure 4. Climatic conditions provide sufficient power to fully solidify the PCM during almost all June and September, which represents the $68 \%$ of the total summer days analysed. These periods are characterized by mild summer conditions [20] (minimum temperatures between $15^{\circ} \mathrm{C}$ and $17^{\circ} \mathrm{C}$ ). However, July and August belong to severe summer conditions, where minimum temperatures are around $20^{\circ} \mathrm{C}-21^{\circ} \mathrm{C}$. Therefore, during several days the power available is lower than the required.

On the other hand, the charging period during winter consists of melting the PCM during the day through the hot air provided by the solar air collector. In this case, solar radiation is the most important input in order to achieve the maximum energy charged. Daily solar energy received in the solar air collector was analysed from measured data of winter season (November to March) and compared to the energy required to melt the PCM. Moreover, the efficiency that the solar air collector $\left(\varepsilon_{\text {col.required }}\right)$ should have to cover the total amount of energy required ( $\mathrm{Q}_{\text {required }}$ ) is calculated by Eq. (3). The evolution of this efficiency is presented in Figure 5, where solar air collector efficiencies of $30 \%$ are enough to cover the energy required during $85 \%$ of winter days.

$\varepsilon_{\text {col.required }}=\frac{Q_{\text {required }}}{Q_{\text {sol }}}$

where,

$Q_{\text {required }}=m_{p c m} \cdot L_{p c m}$

$m_{p c m}$ is the total PCM mass incorporated in the system and $L_{p c m}$ is the latent heat of fusion. These parameters depend on the design of the system and remain constant all year long.

$Q_{\text {sol }}=\int_{t_{i . c h}}^{t_{\text {ech }}} \dot{Q}_{\text {glob-rad }} \cdot d t \cdot A_{\text {col }}$

$A_{c o l}$ is the solar air collector area, $\dot{Q}_{\text {glob-rad }}$ is the incident vertical global solar irradiance between the start of the charge process $\left(t_{i . c h}\right)$ and the end of the process $\left(t_{e . c h}\right)$. The incident vertical global solar irradiance has been studied daily for winter months (from November to March).

\subsection{Theoretical performance}

A theoretical analysis is done to predict the behaviour of the PCM macro-encapsulated in the aluminium tubes, as well as the influence of the concrete slab in the behaviour of the system. A simplified model with no experimental validation was used in this section. Since the aim of this analysis is to have an order of magnitude of the system and not an accurate prediction no experimental validation was required. However, dynamic models can be found in the literature to analyse in detail building-integrated thermal energy storage (BITES) systems [21]. 
As it is well known, concrete is a material with high thermal mass, hence it is supposed to have a significant role in the performance of the active slab. However, each material (concrete and PCM) will behave in a different way when the heat exchange occurs due to air flowing through the hollows of the slab. Hence, the analysis was done separately but under the same initial and final conditions.

For the concrete evaluation the internal surface temperature of the hollows was considered the same as the initial temperature of the PCM $\left(\mathrm{T}_{\mathrm{i} . \mathrm{pcm}}\right)$. Temperature distribution inside the concrete component during initial conditions was calculated with a finite element model. After a mesh independent study a grid based on 2200 elements was used in the numerical model. The internal surface temperature $\left(T_{i . p c m}\right)$, and the internal ambient air temperature $\left(T_{\infty}\right)$ the slab is exposed to, were the fixed parameters. Convective coefficients for the top and bottom of the concrete surface were calculated according to the Nusselt correlation from [22]. Constant temperature airflow $\left(\mathrm{T}_{\infty}\right)$ is circulating through the hollows till concrete temperature drops to airflow temperature. It is considered that the heat exchanges air-concrete and air-PCM are driven by forced convection of internal flow through isothermal surfaces.

The discharging time of the concrete slab is extracted from Eq. (6) that relates the discharge power and the energy stored [23]:

$Q_{\text {concrete }}=P_{\text {concrete }} \cdot \Delta t$

where,

$$
P_{\text {concrete }}=h \cdot A_{\text {hollow }} \cdot \Delta T_{m l}
$$

$h$ is the heat transfer coefficient between the air and the concrete, $A_{\text {hollow }}$ is the area of the concrete slab hollow which is in contact with the air, $\Delta T_{m l}$ is the logarithmic mean temperature difference.

$Q_{\text {concrete }}=m_{\text {concrete }} \cdot C p_{\text {concrete }} \cdot\left(T_{\text {e.concrete }}-T_{\text {i.concrete }}\right)$

$m_{\text {concrete }}$ is total concrete mass, $C p_{\text {concrete }}$ is the concrete specific heat capacity, $T_{\text {e.concrete }}$ is the final temperature of the concrete while $T_{\text {i.concrete }}$ is the initial average temperature of the concrete.

On the other hand, the PCM was also analysed by its own. Initial conditions consider a cylindrical container with PCM at a temperature $\left(T_{i . p c m}\right)$ above the phase change temperature $\left(\mathrm{T}_{\mathrm{pc}}\right)$ which is exposed to an air flow of constant temperature $\left(\mathrm{T}_{\infty}\right)$. Moreover, a correlation of Bilir and Ilken [24] was found in the literature to calculate the solidification time of a phase change material in cylindrical encapsulation and it is applied to this case (Eq. 9). This correlation considers the solidification process of the PCM with a final PCM temperature of $\mathrm{T}_{\infty}$.

$t=\frac{.6496729 \cdot(\text { Ste })^{-0.9439889} \cdot(B i)^{-0.194324} \cdot\left(\theta_{m}\right)^{-0.9548947} \cdot r_{0}{ }^{2}}{\alpha_{s}}$

where, Ste refers to Stefan number, $B$ i to Biot number, $\theta_{m}$ to superheat parameter, $r_{0}$ is the cylinder radius and $\alpha_{s}$ the thermal diffusivity in the solid phase.

Different temperatures for initial conditions of the PCM and concrete, as well as different air inlet temperatures were considered and the results are presented in Table 3. Focusing on the 
discharging time, the PCM lasts 1 hour with air inlet temperature of $18{ }^{\circ} \mathrm{C}$ and 2 hours when the air temperature is kept at $20^{\circ} \mathrm{C}$. On the other hand, the concrete slab has a slower discharge with a discharging time of 5.5 hours and no significant differences when the airflow temperature is changed.

From the results, authors expected that the PCM will provide a fast heating supply, while concrete will slowly discharge its energy contributing to extend the heating supply period.

\section{Experimental set-up}

\subsection{Set-up description}

The new technology was installed and tested in the experimental facility of Puigverd de Lleida (Spain), where side-by-side experiments are carried out under real conditions (Figure 6). A cubicle with internal dimensions of $2.4 \times 2.4 \times 5 \mathrm{~m}$ and constructive system based on alveolar brick is used to perform this experimentation. The active slab consisting on a prefabricated concrete slab with PCM inside its hollows was implemented as internal horizontal separation dividing the cubicle in two storeys. The slab system will be acting in the first floor considering negligible the heat flux towards the second floor.

The cubicle is equipped with two heat pumps (Fujitsu inverter ASHA07LCC), one for each floor, in order to maintain a certain set point temperature in summer and winter periods. Moreover, the cubicle is instrumented with several sensors registering data every 5 min interval:

- Internal surface temperature of walls, roof and floor (Pt-100 DIN B calibrated with a maximum error of $\pm 0.3^{\circ} \mathrm{C}$ ).

- Inside temperature and humidity (ELEKTRONIK EE21 with an accuracy of $\pm 2 \%$ ).

- External temperature and humidity (ELEKTRONIK EE21 with an accuracy of $\pm 2 \%$ ).

- Solar irradiance, horizontal and vertical (Middleton Solar pyranometers SK08 $\pm 2 \mathrm{~W} \cdot \mathrm{m}^{-2}$ ).

- Wind speed and direction (DNA 024 anemometer).

The whole system is instrumented by 20 sensors measuring at different strategic points of the slab with the purpose of analyse and characterize the technology:

- PCM temperatures at different locations inserted inside the aluminium tubes (Pt-100 1/5 DIN B calibrated with a maximum error of $\pm 0.3^{\circ} \mathrm{C}$ ).

- Air temperature and velocity at the inlet and outlet of the slab (KIMO CTV210 with an accuracy of $\pm 0.03 \mathrm{~m} / \mathrm{s}$ and $\pm 0.25^{\circ} \mathrm{C}$ ).

- Air temperature at the inlet and outlet of the solar air collector (Pt-100 1/5 DIN B calibrated with a maximum error of $\pm 0.3^{\circ} \mathrm{C}$ ).

The propagation of errors in the energy values calculated in section 3.2 is $3.9 \%$. 
In this paper, few tests are presented from a preliminary experimental campaign done during March and June 2014. Complete charge and discharge processes are programmed to evaluate the thermal storage capacity and storage efficiency of the active slab. The system operates under different operational schedule depending if it is under winter or summer conditions. Winter profile tests are described below.

$Q_{\text {charge }}=Q_{\text {discharge }}+Q_{\text {loss. passive }}$

Two different parameters have been described to evaluate the efficiency of the technology winter operational mode and is presented in Eq. (12) as the ratio between the energy injected by the collector $\left(Q_{c o l}\right)$ and the energy received by the slab $\left(Q_{\text {charge }}\right)$ : 
$316 \quad \varepsilon_{\text {charge }}=\frac{Q_{\text {charge }}}{Q_{\text {col }}}$

317 where,

$Q_{\text {charge }}=A_{\text {duct }} \cdot C p_{\text {air }} \cdot \int_{t_{i, c h}}^{t_{\text {c.ch }}} \rho_{\text {air }} \cdot v_{\text {air }} \cdot\left(T_{\text {inlet }}-T_{\text {outlet }}\right) \cdot d t$

$Q_{\text {col }}=A_{\text {duct }} \cdot C p_{\text {air }} \cdot \int_{t_{i . c h}}^{t_{\text {ecch }}} \rho_{\text {air }} \cdot v_{\text {air }} \cdot\left(T_{\text {incol }}-T_{\text {outcol }}\right) \cdot d t$

$320 A_{\text {duct }}$ is the sectional area of the air duct, $C p_{\text {air }}$ is the air heat capacity, $\rho_{\text {air }}$ is the air density, $v_{\text {air }}$ is 321 the air velocity, $T_{\text {incol }}$ is the inlet temperature from the collector while the outlet temperature is $322 T_{\text {outcol }}$. The inlet temperature to the slab is $T_{\text {inlet }}$ and the outlet temperature is represented in $T_{\text {outlet }}$.

323 Moreover, the discharge process is also analysed by the parameter $\left(\varepsilon_{\text {discharge }}\right)$ defined in Eq.

324 (15). This parameter is used during both winter and summer periods, and is defined by the 325 amount of energy used to cover the heating/cooling demand $\left(Q_{\text {discharge }}\right)$ and the energy that has 326 been charged in the slab $\left(Q_{\text {charge }}\right)$ :

$\varepsilon_{\text {discharge }}=\frac{Q_{\text {discharge }}}{Q_{\text {charge }}}$

where,

$Q_{\text {disch arge }}=A_{\text {duct }} \cdot c p_{\text {air }} \cdot \int_{t_{i . \text { dis }}}^{t_{\text {dis }}} \rho_{\text {air }} \cdot v_{\text {air }} \cdot\left(T_{\text {outlet }}-T_{\text {inlet }}\right) \cdot d t$

In Eq. $(13,14,16)$ air density $\left(\rho_{\text {air }}\right)$ was determined as a function of temperature for each data registered every 5 min interval.

332 In order to evaluate the performance of the solar air collector, an efficiency parameter $\left(\varepsilon_{c o l}\right)$ is 333 defined in Eq. (17) as the energy injected by the collector $\left(Q_{c o l}\right)$ against the solar energy incident 334 on its vertical surface $\left(Q_{\text {sol }}\right)$. The solar vertical irradiance is registered every 5 min interval with 335 a pyranometer located next to the collector.

$\varepsilon_{c o l}=\frac{Q_{c o l}}{Q_{s o l}}$

where,

$Q_{\text {sol }}=\int_{t_{i . c h}}^{t_{e . c h}} \dot{Q}_{g l o b-r a d} \cdot A_{c o l} \cdot d t$

$A_{c o l}$ is the solar air collector area, $\dot{Q}_{\text {glob-rad }}$ is the incident vertical global solar irradiance between the start of the charge process $\left(t_{i . c h}\right)$ and the end of the process $\left(t_{\text {e.ch }}\right)$.

The charging power of the slab depends on the solar radiation power received and the power injected by the solar air collector. Therefore, the relation between these parameters is evaluated since they can be used as design parameters for the implementation of this system in buildings.

344 During the winter experiments, the heat pumps of the cubicle were turned on all day with a set 345 point temperature of $18{ }^{\circ} \mathrm{C}\left( \pm 0.5^{\circ} \mathrm{C}\right)$. According to the P.O. Fanger comfort curve [19] that 
relates the monthly average temperature to the comfort range temperature, set point of $18{ }^{\circ} \mathrm{C}$ is inside the limit of $80 \%$ of users' acceptance. Authors used this limit temperature in order to analyse the performance of the system by itself and use the heat pump as a support heating supply if internal ambient temperature is below $18{ }^{\circ} \mathrm{C}$. On the other hand, during summer experiments the heat pump was fixed at $25^{\circ} \mathrm{C}\left( \pm 0.5^{\circ} \mathrm{C}\right)$ [19].

\section{Results}

\subsection{Winter period}

\subsubsection{Temperature evolution analysis}

In this paper, four experiments of four consecutive days (from $16^{\text {th }}$ to $19^{\text {th }}$ March) are analysed as winter period mode. During these four days outside temperatures fluctuated between $1{ }^{\circ} \mathrm{C}$ to $26^{\circ} \mathrm{C}$. The daily global irradiation incident on the vertical surface was around $25 \mathrm{MJ} / \mathrm{m}^{2}$. The average maximum and minimum temperatures during March 2014 were $21.4{ }^{\circ} \mathrm{C}$ and $8.4{ }^{\circ} \mathrm{C}$ respectively, with maximum solar vertical irradiance peaks between $400 \mathrm{~W} / \mathrm{m}^{2}$ and $450 \mathrm{~W} / \mathrm{m}^{2}$ during all month.

Temperature behaviour of winter days analysed in this section is presented in Figure 7. At the beginning of the charge period a peak temperature is registered each day and it could be observed in Figure 7, 8 and 9. This fact is due to the hot air coming from the solar air collector that suddenly gets inside the slab. The first breath of air has been stagnant in the solar air collector increasing its temperature to higher values than when air is flowing. Therefore, a temperature peak is registered at the temperature sensor $\mathrm{T}$ inlet. In order to evaluate in detail the temperature evolution the $2^{\text {nd }}$ winter day experiment is presented in Figure 8. It can be seen that the air temperature at the inlet of the slab ( $\mathrm{T}$ inlet) is clearly dependent of the solar radiation period and intensity during the charge period. On the other hand, the PCM temperatures registered at the inlet (PCM inlet) and outlet (PCM outlet) of the slab channels showed different melting rate. The PCM located at the inlet of the slab was completely melted at the end of the charge period, while that located at the outlet was still changing phase. Therefore, the slab has more potential to store energy during days with higher solar radiation.

During the discharge period, the air temperature at the outlet (T outlet) of the slab was always above the set point temperature and was enough to provide the required heating to the cubicle. Therefore, the heat pump was not switched on and the temperature of the internal ambient air ( $\mathrm{T}$ interior) was kept between $20^{\circ} \mathrm{C}$ and $17.5^{\circ} \mathrm{C}$. Moreover, as it happens in the charge period, the PCM located at the inlet of the slab channels has a faster response than that located at the outlet.

Furthermore, Figure 9 shows the thermal evolution of the active slab during winter $4^{\text {th }}$ day of experiment. As it can be observed in the temperature of the inlet air, this day was not as sunny as the $2^{\text {nd }}$ day of experiment presented before. Nevertheless, the PCM at the inlet was also melted and as it happened in the previous experiment, the PCM at the outlet was in its phase change process when the charge period ended. During the discharge period, although the outlet air was always above the minimum set point temperature, at the end of the period (last two hours) it was not enough to keep the internal temperature within the specified range and, therefore, the use of the heat pump was required. This is a consequence of a lower solar radiation energy received this day compared to the other experiments. However, it should be taken into account that the cubicle did not require the heat pump to maintain the set point temperature during $87.5 \%$ of the discharge period. 
It is important to understand the power evolution of both charge and discharge processes in order to implement correctly the system in building designs. Figure 10 presents the power achieved during the charge and discharge periods in the active slab, as well as the solar radiation power received in the solar air collector and the power supplied by this last one. The solar radiation power indicates the vertical solar radiation incident to the solar air collector, which determines the maximum energy that can be absorbed by the system. However, the solar air collector is just absorbing a part of this power depending on its efficiency. The interesting issue is that the slab power during the charge process is very similar to the power injected by the collector, remarking the good charge performance of the system. Therefore, the energy injected in the slab is directly dependent on the solar radiation of each day and hence, the amount of energy charged is dependent too. In Figure 10 the line representing the solar air collector power and the one representing the active slab power are overlaid at some intervals since the active slab charge starts once the solar air collector starts pumping air. Moreover, negative values are presented in the active slab power, which indicate the power during the discharging period.

The energy values of the charge and discharge processes of the slab, as well as the energy received by solar radiation in the solar air collector surface and the energy injected in the slab, are presented in Table 4.

In the winter experiment 2, the solar energy incident on the surface of the collector was 35.64 MJ, this one was able to inject $18.36 \mathrm{MJ}$ and the slab charged 13.56 MJ. The charge efficiency $\left(\varepsilon_{\text {charge }}\right.$ ) of the first three experiments is around $73 \%$ while the last experiment has an efficiency of $64 \%$. This ratio indicates the energy stored by the slab and also the energy lost both through the air ducts when the air is flowing from the collector to the slab and from the slab itself to the cubicle. In this case, a part of the energy losses become direct energy gains since the duct installation is located inside the cubicle and most of the heat losses from the slab are also to the internal ambient air, contributing to its heating.

As it was mentioned before, winter experiment 4 was not as sunny as the previous experiments, and therefore the energy injected (10.02 MJ) and charged (6.43 MJ) were lower. Despite the low energy charged, the discharged energy was similar to the other experiments $(8.97 \mathrm{MJ})$ resulting in a discharge efficiency $\left(\varepsilon_{\text {discharge }}\right)$ of $139 \%$. The slab still had energy stored at the end of the discharge period of the previous day (winter experiment 3), resulting in additional energy available. Figure 11 shows the superficial temperature of the concrete slab. The concrete inlet sensor is located on the side of the slab where the air gets in, while the concrete outlet one is located on the opposite side. The charge and discharge periods are clearly visible in the temperature evolution of the concrete, and hence, both processes can be compared in the four experiments. It can be observed that the minimum slab temperature during the discharge period is slightly increasing during the first three days, and the last day is significantly above the other experiments. Thus, the concrete, thanks to its high thermal inertia, is storing a part of the energy charged without discharging it. Once there is a day with low solar radiation and consequently low energy charged, such as winter experiment 4 , the additional energy stored in the concrete is discharged.

430 In section 2.4, theoretical analysis showed an important difference on the discharge time 431 between the PCM and the concrete, which is reflected in the experimental results. Concrete 
thermal mass is contributing to increase the thermal inertia of the system through the slow discharge rate.

434 Regarding the solar air collector, its efficiency $\left(\varepsilon_{c o l}\right)$ is defined by the relation between the 435 energy injected and the solar radiation received on the vertical surface. This ratio is around $50 \%$ 436 for the first three experiments and $36 \%$ for the last one. The performance of the solar air 437 collector depends on the external temperatures, having an average temperature around $20{ }^{\circ} \mathrm{C}$ during the charge period of the first days and $16^{\circ} \mathrm{C}$ for the last experiment.

439 The efficiency parameters define the performance of the technology which can be useful for the 440 implementation in buildings under different weather conditions or climates. Once the solar 441 radiation data of the location are known, these values become design parameters and the heating 442 load covered by the system can be estimated.

443 It is also important to mention that during these experiments the fan has been working $24 \mathrm{~h} /$ day, 444 consuming $1.7 \mathrm{kWh} /$ day. The operational profile of the active slab in these experiments was not optimized, as the experiments were designed to proof the concept and to assess its charge and discharge processes. Therefore, an optimization of the fan operation is required in order to decrease its energy consumption.

\subsection{Summer period}

\subsubsection{Temperature evolution}

Preliminary results have been analysed from the experimental campaign of summer 2014. Maximum outside temperatures during these experiments were between $36{ }^{\circ} \mathrm{C}$ and $32{ }^{\circ} \mathrm{C}$, while minimum temperatures were around $14{ }^{\circ} \mathrm{C}$. Solar global horizontal irradiance had maximum values around $950 \mathrm{~W} / \mathrm{m}^{2}$. These experiments had representative weather conditions from June 2014 in this area, since the maximum average temperatures fluctuated between $28{ }^{\circ} \mathrm{C}$ to $32{ }^{\circ} \mathrm{C}$, and the minimum ones were between $12{ }^{\circ} \mathrm{C}$ to $15^{\circ} \mathrm{C}$. Moreover, maximum daily values from solar global horizontal irradiance were between $950 \mathrm{~W} / \mathrm{m}^{2}$ and $1100 \mathrm{~W} / \mathrm{m}^{2}$.

The fourth consecutive experiments are shown in Figure 12, while temperature evolution of the slab during summer experiment 1 is presented in Figure 13. Air inlet temperature drops to $16{ }^{\circ} \mathrm{C}$ at the end of the charging period providing cold for the PCM solidification process. At this point, PCM at the inlet is completely solidified, but not the one at the outlet. During the storage period (from $07 \mathrm{~h}$ to $11 \mathrm{~h}$ ) PCM inlet temperature rises up $1{ }^{\circ} \mathrm{C}$ which means there is absorption of heat (losses of cold energy stored). Nevertheless, the heat absorbed comes from the internal ambient due to the integration of the slab inside the building, providing a passive cooling supply. This fact is reflected in the interior temperature which decreases during the storage period. This effect is an improvement compared to similar systems studied before, such a double skin facade with PCM [25], which stored the cold in an external envelope of the building where the cold stored was subjected to heat gains from the outer environment.

Moreover, when the discharge period starts the supply air (T outlet) is around $22{ }^{\circ} \mathrm{C}$ providing 470 cooling to the inner environment ( $\mathrm{T}$ interior). Even the PCM inlet is fully melted at the middle of the discharge period, the PCM outlet remains in the phase change range so the air at the outlet of the slab is able to supply some cooling to the internal ambient. It should be mentioned that internal ambient temperature was kept under $25^{\circ} \mathrm{C}\left( \pm 0.5^{\circ} \mathrm{C}\right)$ during all day without any conventional cooling system, just with the active slab supply. 
476 Energy values during the charge and discharge period are presented in Table 5. During these

477 experiments, discharge efficiency values are quite low, oscillating from $17 \%$ to $6 \%$. An

478 important part of the energy charged during night time is lost in the storage period. However, as

479 it was previously mentioned, since the storage system is located inside the building, cold losses

480 are contributing to cool down the internal ambient and the storage period becomes a passive

481 cooling period.

482 The same fact as in winter experiments is happening during summer, the operating performance 483 of the system is not optimized, hence the fan is consuming $2.3 \mathrm{kWh} /$ day since it is working 7

$484 \mathrm{~h} /$ day with the highest air flow velocity.

\section{Conclusions}

An innovative active slab consisting of a prefabricated concrete slab with PCM inside its hollows is presented in this paper. A prototype of this new technology was implemented as internal slab of a house-like cubicle located in the experimental facility of the University of 490 Lleida (Spain).

491 The design parameters which define the available energy that the system can charge in the PCM 492 were analysed in the Mediterranean continental climate. In the summer mode, almost $70 \%$ of the summer days, the active slab is able to completely charge $100 \%$ of the PCM. On the other hand, in the winter period a solar air collector with an efficiency of $30 \%$ will be enough to have successful charge processes during all the winter season.

The performance of the concept under winter and summer conditions was tested during March and June 2014 respectively, and the results obtained show its potential and warrant further research under operating conditions.

The active slab was tested under mild winter conditions and an interesting potential is observed in the results, where charge and discharge efficiencies around 70\% were registered. Moreover,

501 the theoretical performance of the system discharge suggested that the PCM will provide a fast

502 heating supply, while concrete will slowly discharge its energy contributing to extend the

503 heating supply period which was proved in the experimental winter results. The energy charged

504 in the slab which is not used the same day is stored and becomes useful during days with low

505 charged energy. This fact is due to the high thermal mass of the concrete and its low discharge

506 rate proved in the theoretical and experimental results.

507 Furthermore, the active slab was also tested under mild summer conditions and experiments 508 showed low discharge efficiencies, which are mainly attributed to the energy losses during the 509 storage period.

510 In both winter and summer modes energy losses were registered during charge or storage 511 periods. An important part of the energy lost through air ducts or convection in the slab became 512 direct energy gains (heating or cooling) to the internal ambient since the system is integrated in 513 the building. 
514 The potential of the system to store and provide a heating and cooling supply has been 515 demonstrated. However, it should be taken into account that the operational profiles of the 516 presented experiments were designed to assess its potential. Authors concluded that a control 517 system is needed in order to manage the charge, discharge and storage processes in order to 518 optimize the use of the fan. The implementation of operating programs which depends on the 519 weather conditions and the energetic requirements could maximize the efficiency of the 520 technology. Finally, the promising results obtained in this paper warrant further research on experimental complete campaign under different scenarios and weather conditions.

522

523

524

525

526

527

528

529

530

531

532

533

534

535

536

537

538

539

540

541

542

543

544

\section{Acknowledgements}

This work was supported by the "Corporación Tecnológica de Andalucía" by means of the project "MECLIDE-Soluciones estructurales con materiales especiales para la climatización diferida de edificios" with the collaboration of DETEA. The work partially funded by the Spanish government (ENE2011-28269-C03-01 and ULLE10-4E-1305). The authors would like to thank the Catalan Government for the quality accreditation given to their research group (2014 SGR 123) and the city hall of Puigverd de Lleida. The research leading to these results has received funding from the European Union's Seventh Framework Programme (FP7/20072013) under grant agreement $n^{\circ}$ PIRSES-GA-2013-610692 (INNOSTORAGE).

\section{References}

[1] Directive 2010/31/EU of the European parliament and of the council of 19 May 2010 on the energy performance of buildings. Available from: http://www.epbd-ca.eu.

[2] Horizon 2020, The EU Framework Programme for Research and Innovation. Available from: http://ec.europa.eu/programmes/horizon2020/en/ (April 2014).

[3] Shukla R, Sumathy K, P. Erickson, Gong J. Recent advances in the solar water heating systems: A review. Renewable and Sustainable Energy Reviews 2013;19:173-90.

[4] Mahliaa TMI, Saktisahdana TJ, Jannifarc A, Hasanc MH, Matseelarc HSC. A review of available methods and development on energy storage; technology update. Renewable and Sustainable Energy Reviews 2014;33:532-45.

[5] Yau YH, Rismanchi B. A review on cool thermal storage technologies and operating strategies. Renew Sustain Energy Rev2012;16:787-97.

[6] Mehling H, Cabeza LF. Heat and cold storage with PCM. Springer: Berlin; 2008.

[7] Zhou D, Zhao CY, Tian Y. Review on thermal energy storage with phase change materials (PCMs) in building applications. Applied Energy 2012;92:593-605.

[8] Zalba B, Marín JM, Cabeza LF, Mehling H. Review on thermal energy storage with phase change: Materials, heat transfer analysis and applications, Applied Thermal Engineering 2003;23:251-83.

[9] Cabeza LF, Castell A, Barreneche C, de Gracia A, Fernández AI. Materials used as PCM in thermal energy storage in buildings: A review, Renewable and Sustainable Energy Reviews 2011;15:1675-95. 
552 [10] Mandilaras I, Stamatiadou M, Katsourinis D, Zannis G, Founti M. Experimental thermal 553 characterization of a Mediterranean residential building with PCM gypsum board walls. 554 Building and Environment 2013;61:93-103.

555 [11] Cabeza LF, Castellon C, Nogues M, Medrano M, Leppers R, Zubillaga O. Use of 556 microencapsulated PCM in concrete walls for energy savings. Energy Build 2007;39:113-9.

557 [12] Castell A, Martorell I, Medrano M, Pérez G, Cabeza LF. Experimental study of using PCM 558 in brick constructive solutions for passive cooling. Energy and Buildings 2010;42(4):534-40.

559 [13] Lazaro A, Dolado P, Marin JM, Zalba B. PCM-air heat exchangers for free-cooling 560 applications in buildings: Empirical model and application to design. Energy Conversion and 561 Management 2009;50(3):444-9.

562 [14] Castell A, Solé C, Medrano M, Nogués M, Cabeza LF. Comparison of stratification in a 563 water tank and a PCM-water tank. Journal of Solar Energy Engineering, Transactions of the 564 ASME 2009;131(2):0245011-0245015.

565 [15] Hamada Y, Fukai J. Latent heat thermal energy storage tanks for space heating of 566 buildings: Comparison between calculations and experiments. Energy Conversion and 567 Management 2005;46:3221-35.

568 [16] de Gracia A, Navarro L, Castell A, Ruiz-Pardo A, Álvarez S, Cabeza LF, Experimental 569 study of a ventilated facade with PCM during winter period. Energy and Buildings $570 \quad 2013 ; 58: 324-32$.

571 [17] Barton P, Beggs CB, Sleigh PA. A theoretical study of the thermal performance of the 572 TermoDeck hollow core slab system. Applied Thermal Engineering 2002;22:1485-99.

573 [18] Pomianowski M, Heiselberg P, Jensen RL. Dynamic heat storage and cooling capacity of a 574 concrete deck with PCM and thermally activated building system. Energy and Buildings $575 \quad 2012 ; 53: 96-107$.

576 [19] Non-residential cooling and heating load calculations. In: Parsons RA, editor. Ashrae 577 Handbook Fundamentals, Atlanta: American Society of Heating, Refrigerating and Air578 Conditioning Engineers, Inc.; 1997, p.28.7-28.16.

579 [20] de Gracia A, Navarro L, Castell A, Boer D, Cabeza LF. Life cycle assessment of a 580 ventilated facade with PCM in its air chamber. Solar Energy 2014;104:115-23.

581 [21] Yuxiang Chen, Galal KE, Athienitis AK. Design and operation methodology for active 582 building-integrated thermal energy storage systems. Energy and Buildings 2014;84:575-585.

583 [22] Wong HY. Heat transfer for Engineers, Chapter 3. Free and forced convection heat transfer 584 formulae. Longman: London; 1977.

585 [23] Incropera FP, DeWitt DP. Fundamentals of Heat and Mass Transfer. $4^{\text {th }}$ edition Wiley: 586 New York;1996.

587 [24] Bilir L, Ilken Z. Total solidification time of a liquid phase change material enclosed in 588 cylindrical/spherical containers. Applied Thermal Engineering 2005;25:1488-1502. 
589 [25] de Gracia A, Navarro L, Castell A, Ruiz-Pardo A, Álvarez S, Cabeza LF. Thermal analysis 590 of a ventilated double skin facade with PCM for cooling applications. Energy and Buildings $591 \quad 2012 ; 65: 508-15$.

592

593 


\begin{tabular}{|c|c|}
\hline$A_{c o l}$ & Area of the solar air collector $\left[\mathrm{m}^{2}\right]$ \\
\hline$A_{\text {duct }}$ & Sectional area of the air duct $\left[\mathrm{m}^{2}\right]$ \\
\hline$A_{\text {hollow }}$ & Area of the hollow of the concrete slab in contact with the air $\left[\mathrm{m}^{2}\right]$ \\
\hline$B i$ & Biot number $\left(=\frac{h \cdot r_{0}}{k_{s}}\right)$ \\
\hline$c p_{\text {air }}$ & Air heat capacity $\left[\mathrm{J} \cdot \mathrm{kg}^{-1} \cdot \mathrm{K}^{-1}\right]$ \\
\hline$c p_{s}$ & Specific heat capacity PCM (solid phase) $\left[\mathrm{J} \cdot \mathrm{kg}^{-1} \cdot \mathrm{K}^{-1}\right]$ \\
\hline$h$ & Heat transfer coefficient $\left[\mathrm{W} \cdot \mathrm{m}^{-2} \cdot \mathrm{K}^{-1}\right]$ \\
\hline$I$ & Daily irradiance $\left[\mathrm{W} \cdot \mathrm{m}^{-2}\right]$ \\
\hline$k_{s}$ & Thermal conductivity (solid phase) $[\mathrm{W} / \mathrm{m} \cdot \mathrm{K}]$ \\
\hline$L_{p c m}$ & Latent heat of fusion $\left[\mathrm{J} \cdot \mathrm{kg}^{-1}\right]$ \\
\hline$m_{\text {concrete }}$ & Total concrete mass $[\mathrm{kg}]$ \\
\hline$m_{p c m}$ & Total PCM mass $[\mathrm{kg}]$ \\
\hline$\dot{m}$ & Mass flow rate $\left[\mathrm{kg} \cdot \mathrm{s}^{-1}\right]$ \\
\hline$P_{\text {available }}$ & Daily available power achieved from temperatures below $21{ }^{\circ} \mathrm{C}[\mathrm{W}]$ \\
\hline$P_{\text {concrete }}$ & Discharge power of the concrete slab $[\mathrm{W}]$ \\
\hline$P_{\text {required }}$ & Daily required power to solidify the PCM [W] \\
\hline$Q_{\text {available }}$ & Energy available in the solar air collector $[\mathrm{kWh}]$ \\
\hline$Q_{\text {charge }}$ & Total stored heat in the active slab $[\mathrm{J}]$ \\
\hline$Q_{c o l}$ & Total injected heat supplied from the solar air collector $[\mathrm{J}]$ \\
\hline$Q_{\text {concrete }}$ & Energy stored by the concrete slab [Wh] \\
\hline$Q_{\text {discharge }}$ & Total provided heat by the active slab $[\mathrm{J}]$ \\
\hline$Q_{\text {loss.col }}$ & Energy losses during the charging period $[\mathrm{J}]$ \\
\hline$Q_{\text {loss.passive }}$ & Energy losses during the discharging period $[\mathrm{J}]$ \\
\hline$Q_{\text {required }}$ & Energy required to melt the total amount of PCM $[\mathrm{kWh}]$ \\
\hline$Q_{\text {sol }}$ & Total solar energy incident in the solar air collector $[\mathrm{J}]$ \\
\hline$\dot{Q}_{\text {glob_rad }}$ & Incident vertical global solar irradiance $\left[\mathrm{W} \cdot \mathrm{m}^{-2}\right]$ \\
\hline$r_{0}$ & Cylinder radius [m] \\
\hline
\end{tabular}


Stefan number $\left(=\frac{c p_{s} \cdot\left(T_{i . p c m}-T_{\infty}\right)}{L}\right)$

$T_{\text {av.out }}$

$T_{\text {e.concrete }}$

$T_{\text {e.air }}$

$T_{\text {i.concrete }}$

$T_{i, p c m}$

$T_{\infty}$

$T_{p c}$

$T_{\text {inlet }}$

$T_{\text {outlet }}$

$T_{\text {incol }}$

$T_{\text {outcol }}$

$T_{\text {interior }}$

$t_{\text {av.out }}$

$t_{\text {i.ch }}$

$t_{e . c h}$

$t_{i d i s}$

$t_{\text {e.dis }}$

$v_{\text {air }}$

Greek symbols
Average outside temperature below $21{ }^{\circ} \mathrm{C}[\mathrm{K}]$

Final temperature of the concrete $[\mathrm{K}]$

Mean temperature of the air at the outlet of the hollow [K]

Initial average temperature of the concrete $[\mathrm{K}]$

Initial temperature of the PCM $[\mathrm{K}]$

Internal ambient air temperature $[\mathrm{K}]$

Phase change temperature $[\mathrm{K}]$

Temperature at the inlet of active slab $[\mathrm{K}]$

Temperature at the outlet of active slab [K]

Temperature at the inlet of the solar air collector [K]

Temperature at the outlet of the solar air collector $[\mathrm{K}]$

Temperature of internal ambient of the cubicle $[\mathrm{K}]$

Period of time where outside temperature is below $21^{\circ} \mathrm{C}[\mathrm{h}]$

Time start of charge process [s]

Time end of charge process [s]

Time start of discharge process [s]

Time end of discharge process [s]

Air velocity $\left[\mathrm{m} \cdot \mathrm{s}^{-1}\right]$
$\Delta T_{m l}$
$\alpha_{s}$
$\theta_{m}$
$\rho_{\text {air }}$
Logarithmic mean temperature difference $[\mathrm{K}]\left(=\frac{T_{\text {e.air }}-T_{\infty}}{\ln \frac{T_{\text {i.pcm }}-T_{\text {e.air }}}{T_{\text {e.air }}-T_{\infty}}}\right)$ thermal diffusivity in the solid phase $\left[\mathrm{m}^{2} \cdot \mathrm{s}^{-1}\right]$
Superheat parameter $\left(=\frac{T_{p c}-T_{\infty}}{T_{i . p c m}-T_{\infty}}\right)$
Air density $\left[\mathrm{kg} \cdot \mathrm{m}^{-3}\right]$ 


$\begin{array}{ll}\varepsilon_{\text {charge }} & \text { Charge efficiency } \\ \varepsilon_{\text {discharge }} & \text { Discharge efficiency } \\ \varepsilon_{\text {col }} & \text { Solar air collector efficiency } \\ \varepsilon_{\text {col.required }} & \text { Solar air collector efficiency required }\end{array}$

595

596 